\title{
Emodin induces apoptosis of human cervical cancer hela cells via intrinsic mitochondrial and extrinsic death receptor pathway
}

\author{
Wang Yaoxian ${ }^{1,2}$, Yu Hui ${ }^{3}$, Zhang Yunyan ${ }^{1}$, Liu Yanqin ${ }^{1}$, Ge Xin ${ }^{4}$ and Wu Xiaoke $2^{2^{*}}$
}

\begin{abstract}
Background: Emodin is a natural anthraquinone derivative isolated from the Rheum palmatum L. Aim: The aim of the present study was to investigate the effect of emodin on the apoptosis of the human cervical cancer line HeLa and to identify the mechanisms involved.

Methods: Relative cell viability was assessed by MTT assay after treatment with emodin. Cell apoptosis was detected with TUNEL, Hoechst 33342 staining and quantified with flow cytometry using annexin FITC-PI staining.

Results: The percentage of apoptotic cells was $0.8,8.2,22.1$, and $43.7 \%$, respectively. The mRNA levels of Caspase-9, -8 and -3 detected by Real-time PCR after treatment with emodin were significantly increased. Emodin increased the protein levels of Cytochome $c$, Apaf-1, Fas, FasL, and FADD but decreased the protein levels of Pro-caspase-9, Procaspase-8 and Pro-caspase-3.

Conclusion: We conclude that the emodin inhibited HeLa proliferation by inducing apoptosis through the intrinsic mitochondrial and extrinsic death receptor pathways.
\end{abstract}

Keywords: Emodin, HeLa cells, Tunel, Flow cytometry, Apoptosis

\section{Introduction}

Cervical cancer is the second female cancer worldwide as the most common malignancy in both incidence and mortality [1]. More than $80 \%$ of cases are found in developing countries [2]. There are several treatments used for cervical cancer, but each of them has apparent drawbacks. Surgical treatment is restricted only for patients with early stage and the young patients who have lost fertility [3]. Radiotherapy and chemotherapy are not specific to cancer cells and often bring severe adverse effect, including bone marrow suppression, nerve injury, gastrointestinal adverse reactions, renal impairment and second cancer occurrence [3]. Although the technology and method become more and more advanced, up to $35 \%$ patients will still develop persistent/recurrence/ metastatic disease when the treatment results are poor. New therapeutic strategies must be evaluated to improve

\footnotetext{
* Correspondence: xiaoke.wu@aliyun.com

${ }^{2}$ Department of Gynecology, First Affiliated Hospital of Heilongjiang University of Chinese Medcine, Hapin Road, 150040, Haerbin, Heilongjiang Province, China

Full list of author information is available at the end of the article
}

survival. Thus, finding a safer and more efficient treatment remains an arduous task.

Recent studies have focused on the anti-tumor properties of natural products because these medicines have fewer side-effects and are more suitable for long-term use compared with chemically synthesized medicines. Emodin (1, 3, 8-trihydroxy-6-methyl-anthraquinone), a naturally occurring anthraquinone, present in the roots and barks of numerous plants, is an active ingredient of various Chinese herbs including Rheum officinale and Polygonam cuspidatummedicine [4]. Pharmacological studies have demonstrated that emodin possesses antibacterial [5], anti-inflammatory [6], immuno-suppressive [7], and anti-cancer effects [8]. In vitro and in vivo studies have demonstrated its potential as an excellent cytotoxicity against a variety of malignant human cancers such as lung cancer [9], chronic myelocytic leukemia [10], liver cancer [11], tongue squamous cancer [12], gastric cancer [13], prostate cancer [14] and gallbladder cancer [15] but emodin have almost no toxic effect on normal cells $[16,17]$. However, the molecular mechanisms for the growth 
inhibition and cytotoxicity of emodin-treated HeLa cells are poorly understood.

In recent years, apoptosis has emerged as the major mechanism by which anticancer agents eliminate preneoplastic or neoplastic cells. It has been proven that emodin can induce apoptosis through increasing nuclear condensation and DNA fragmentation $[18,19]$, activating caspase -9 and -3 [20], inducing cell-cycle arrest [12,21], elevating level of ROS [22,23], decreasing level of NF-KB $[24,25]$, activating PI3K/AKT pathway [26] and PKC pathway [20,27], However, there is no available information to address how emodin affects human cervical cancer cells in vitro. The aim of the present study is to investigate the potential anticancer effects of emodin on human cervical cancer cells and the underlying molecular mechanisms.

\section{Materials and methods}

\section{Chemicals and reagents}

Emodin and MTT [3-(4, 5-dimethylthiazol-2-yl)-2, 5diphenyltetrazolium bromide] were obtained from Sigma Chemical Co. (USA). The primers of caspase-8, 9 and -3 for Real-time PCR were purchased from Genscript (China). Antibodies against Cytochrome $c$, Apaf-1, Caspase-9, Fas, FasL, FADD, Caspase-8, Caspase3 , Gapdh and $\beta$-actin were purchased from Cell Signaling Technology (USA). Fluorescence-conjugated secondary antibodies were purchased from Invitrogen (USA). Other chemicals were obtained in their commercially available highest purity grade.

\section{Cell culture}

The human cervical cancer HeLa cells were obtained from American Type Culture Collection (ATCC). Cells were cultured in Dulbecco's modified Eagle's medium supplemented with $10 \%(\mathrm{v} / \mathrm{v})$ fetal calf serum, $100 \mu \mathrm{g} / \mathrm{mL}$ streptomycin, and $100 \mathrm{U} / \mathrm{mL}$ penicillin. Cultures were maintained at $37^{\circ} \mathrm{C}$ in a humidified incubator in an atmosphere of $5 \% \mathrm{CO}_{2}$.

\section{MTT assay for cell proliferation}

Cell proliferation was determined by MTT assay. In brief, the HeLa cells in logarithmic phase were seeded into 96 -well plate at $1 \times 10^{4}$ cells/well followed by incubation at $37^{\circ} \mathrm{C}$ for $24 \mathrm{~h}$ for attachment and then treated with emodin $(0,10,20,30,40$ and $50 \mu \mathrm{M})$ for 24,48 or $72 \mathrm{~h}$, respectively. Six wells were included in each group. $20 \mu \mathrm{L}$ of $5 \mathrm{mg} / \mathrm{mL}$ MTT dye was added to each well and incubated at $37^{\circ} \mathrm{C}$ for $4 \mathrm{~h}$. Then the supernatant was discarded and purple-colored precipitates of formazan were dissolved by gently shaking for $10 \mathrm{~min}$ in $150 \mu \mathrm{L}$ of dimethyl sulfoxide (DMSO). After complete dissolution, absorbance (A) was measured at $490 \mathrm{~nm}$ on a microplate reader. The effect of emodin on growth inhibition was assessed as the percentage of inhibition in cell growth. Background absorbance of the medium in the absence of cells was subtracted. Percent viability was calculated as [value of drug-treated group (A)/control group (A)] $\times$ $100 \%$. Each assay was carried out three times, and the results were expressed as the mean $( \pm$ SEM). Similar results were observed in at least three independent experiments.

\section{Detection of apoptotic cells by TUNEL and Hoechst 33342 staining}

The apoptotic HeLa cells were detected using the TUNEL assay that was performed using an in Situ Nick-End Labeling kit (Beyotime Institute of Biotechnology, China). Cells were treated with emodin $(0,20,40$ and $80 \mu \mathrm{M})$ in 96well plates. After $48 \mathrm{~h}$, the attached cells were washed with PBS and then fixed in freshly prepared $4 \%$ paraformaldehyde for $30 \mathrm{~min}$, then washed with PBS and incubated with digoxigenin-conjugated dUTP in a terminal deoxynucleotidyl transferase-catalyzed reaction for $1 \mathrm{~h}$ at $37^{\circ} \mathrm{C}$ in a humidified atmosphere. After the cells were immersed in stop/wash buffer for $10 \mathrm{~min}$ at room temperature and washed with PBS, they were incubated with an anti-digoxigenin antibody conjugating peroxidase for $30 \mathrm{~min}$. The nuclei fragments were stained using 3, 3'-diaminobenzidine (DAB) as a substrate of the peroxidase for $5 \mathrm{~min}$. Apoptotic cells were stained brown.

The apoptosis of HeLa cells was also detected using the Hoechst 33342 assay kit (Beyotime Institute of Biotechnology, China). The HeLa cells were seeded on coverslips on a 6-well plate and treated with emodin $(0,20$, 40 and $80 \mu \mathrm{M})$. After $48 \mathrm{~h}$, the attached cells were washed with PBS and fixed in freshly prepared $4 \%$ paraformaldehyde for $30 \mathrm{~min}$, then washed with PBS and incubated with Hoechst 33342 staining solution for $5 \mathrm{~min}$. After treatment, cells were washed with PBS and added Antifade Mounting Medium, then detected the apoptosis by fluorescence microscope. Apoptosis, with condensed and fragmented nuclei, was observed under fluorescence microscope.

\section{Quantification of apoptosis by flow cytometry}

The apoptotosis of HeLa cells was quantified using flow cytometry. After incubation with emodin $(0,20,40$ and $80 \mu \mathrm{M})$ in six-well plates for $48 \mathrm{~h}$, the cells were harvested with trypsin treatment and centrifugation, washed with PBS, stained with $10 \mu \mathrm{L}$ annexin V-FITC and $5 \mu \mathrm{L}$ propidium iodide (PI) in the dark at room temperature for $15 \mathrm{~min}$ according to the manufacturer's protocol (Biosea, China) and then analyzed with Becton FACSC flow cytometer (Becton Dickinson Corporation, USA). For each condition, $1 \times 10^{4}$ cells were studied in each cytometry experiment. 


\section{RNA isolation and real-time PCR analysis}

Total RNA was extracted by a Trizol reagent kit (Invitrogen, USA) after the HeLa cells treated with emodin $(0,20,40$ and $80 \mu \mathrm{M})$ for $48 \mathrm{~h}$. The quality of each RNA sample (including its concentration and purity) was checked by measuring the absorbance. One microgram RNA from each sample was used to generate cDNA using M-MLV reverse transcriptase as per manufacturer's specifications (Promega Corporation, USA). After an initial denaturation step at $95^{\circ} \mathrm{C}$ for 10 min using SYBR Green PCR Master Mix (Applied Biosystems, USA), Real-time PCR was cycled 40 times between $95^{\circ} \mathrm{C} / 15 \mathrm{~s}$ and $60^{\circ} \mathrm{C} / 1 \mathrm{~min}$. Amplification was performed using 7500 Fast Real-Time PCR Systems (Applied Biosystems, USA) and the products were routinely checked using dissociation curve software. Transcript quantities were compared by the relative $\mathrm{Ct}$ method and the amount of Caspase-9, -8 and -3 were normalized to the endogenous control (GAPDH). The value in relation to the control sample was given by $2-\Delta \Delta \mathrm{CT}$. Real-time PCR primer sequences for caspases measurements were as following:

Caspase 9: sense: 5' -CGAACTAACAGGCAAGCAG C-3' anti-sense: 5' -ACCTCACCAAATCCTCCAGAAC-3';

Caspase 8: sense: 5'-GCCTCCCTCAAGTTCCT-3' anti-sense: 5' -CCTGGAGTCTCTGGAATAACA-3';

Caspase 3: sense: 5'-TGGTTCATCCAGTCGCTTTG3' anti-sense: 5' -CATTCTGTTGCCACCTTTCG-3'.

\section{Western blot analysis}

Following treated with emodin $(0,20,40$ and $80 \mu \mathrm{M})$ for $48 \mathrm{~h}$, HeLa cells were washed with ice-cold PBS and collected in lysis buffer including $50 \mathrm{mM}$ Tris, $\mathrm{pH} 7.4$, $150 \mathrm{mM} \mathrm{NaCl}, 1 \% \mathrm{NP}-40,0.25 \%$ sodium deoxycholate, 0.1\% SDS, $1 \mathrm{mM} \mathrm{Na} \mathrm{VO}_{4}, 1 \mathrm{mM} \mathrm{NaF}, 1 \mathrm{mM}$ EDTA, $1 \mathrm{mM}$ PMSF and $1 \mu \mathrm{g} / \mathrm{mL}$ leupeptin. The supernatant was obtained by centrifuging at 13,500 rpm for $20 \mathrm{~min}$. Total protein was extracted and protein concentration was determined by Bradford assay. For immunoblotting, $120 \mu \mathrm{g}$ proteins from each sample were subjected to electrophoresis on 12\% SDS-PAGE and separated proteins were transferred onto a PVDF membrane. The PVDF membrane was blocked with 5\% non-fat milk powder $(\mathrm{w} / \mathrm{v})$ at room temperature for $2 \mathrm{~h}$, then incubated with the primary antibodies against Cytochrome c (1:500), Apaf-1 (1:500), Caspase-9 (1:500), Fas (1:500), FasL (1:500), FADD (1:500), Caspase-8 (1:500), Caspase-3 (1:500), Gapdh (1:1000), and $\beta$-actin (1:500), respectively, at $4^{\circ} \mathrm{C}$ overnight. After washing, the membrane was incubated with fluorescence-conjugated secondary antibody (anti-rabbit or anti-mouse, 1:10000; Invitrogen, USA) at room temperature for $50 \mathrm{~min}$. Gapdh or $\beta$-actin was used as an internal control to monitor equal protein loading and transfer of proteins from the gel to the membranes after stripping them with the Gapdh and $\beta$-actin antibodies. Western blot bands were quantified using the Odyssey infrared imaging system (LI-COR, USA). All results represent of three independent experiments.

\section{Statistical analysis}

Data were reported as means \pm SEM of at least three independent experiments. For statistical analysis, one-way ANOVA was used for comparison of one variance among groups and two-way ANOVA was used for comparison of two independent variances among groups followed by the Tukey post hoc test. A P value less than 0.05 was considered to be significant.

\section{Results}

Emodin-induced morphological changes and antiproliferation of HeLa cells

The morphology of the HeLa cells was examined using a phase contrast microscope. In the presence of emodin, HeLa cells showed round morphology with small shrinkage and nuclear condensation, a proportion of the cells revealed swelling, cell membrane lysis and disintegration of organelles, suggesting emodin-induced toxicity to HeLa cells (pictures not shown). HeLa cells were incubated with emodin $(0,10,20,30,40$ and $50 \mu \mathrm{M})$ and cell viability was evaluated by the MTT assay at 24, 48 and $72 \mathrm{~h}$. Treatment with 10, 20, 30, 40 and $50 \mu \mathrm{M}$ emodin significantly reduced cell viability compared to the control group (Figure 1), indicating a dose-dependent effect of emodin on cell viability. Among all the tests, cells incubated with $50 \mu \mathrm{M}$ emodin for $72 \mathrm{~h}$ showed the maximum

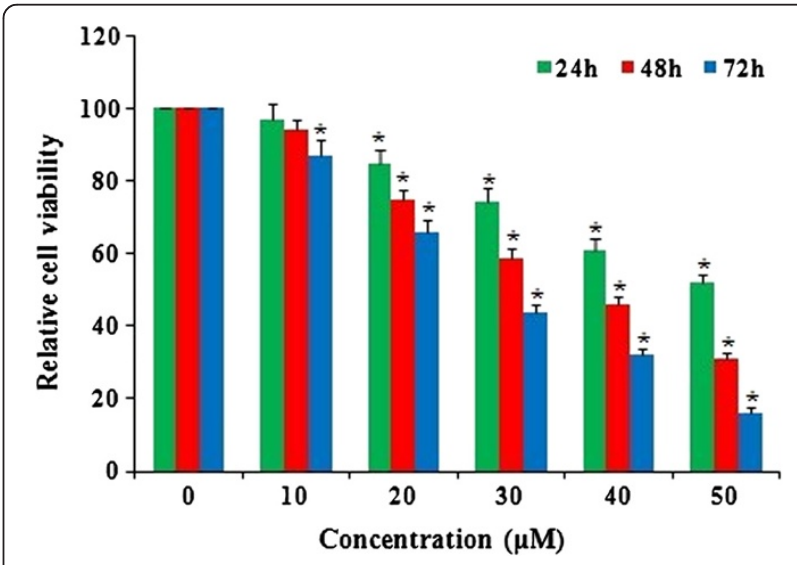

Figure 1 Emodin-induced anti-proliferation of HeLa cells. HeLa cells were treated with emodin at doses of $0,10,20,30,40$, and 50 $\mu \mathrm{M}$ for 24,48 , and $72 \mathrm{~h}$. Cell viability was evaluated with the MTT assay and results are reported as relative cell viability (\%). All data were normalized to the control group which was considered to be $100 \%$. The result showed that emodin inhibited proliferation of HeLa cells in a dose- and time-dependent manner. ${ }^{*} \mathrm{P}<0.05$ versus control group $(0 \mu \mathrm{M})$ (two-way ANOVA followed by the Tukey post hoc test). 
anti-proliferation effect, with cell viability decreased to $16 \%$ of the control cells. These results suggest that emodin inhibits proliferation of HeLa cells in a dose- and time-dependent manner.

\section{Emodin-induced apoptosis of HeLa cells}

The TUNEL and Hoechst 33342 apoptosis detection kit were used after cells were treated with emodin $(0,20,40$ and $80 \mu \mathrm{M})$ for $48 \mathrm{~h}$. Representative images of TUNEL and Hoechst 33342 staining were shown in Figures 2 and 3. The number of apoptotic HeLa cells (white arrows) increased with the dose of emodin. Apoptotic HeLa cells displayed a round and shrunken cell body, suggesting that emodin-induced apoptosis of HeLa cells might contribute to reduced cell viability.

To further quantify emodin-induced apoptosis of HeLa cells, cells were stained with annexin V-FITC and PI, followed by flow cytometry. A representative result of flow cytometry was presented in Figure 4a. The lower right quadrant (Q4) depicts the percentage of early apoptotic cells (annexin V-FITC-stained cells) and the upper right quadrant $(\mathrm{Q} 2)$ represents the percentage of late apoptotic cells (annexin V-FITC and PI-stained cells). The fully apoptotic cells are those in the lower right and upper right quadrants. As shown in the quantitative result in Figure 4b, only a small number of apoptotic cells was detected in the control group. However, $48 \mathrm{~h}$ after treatment with $0,20,40$ and $80 \mu \mathrm{M}$ emodin, cell apoptosis was $0.8,8.2,22.1$, and $43.7 \%$, respectively. These results suggest that emodin induced significant apoptosis of HeLa cells in a dose-dependent manner.

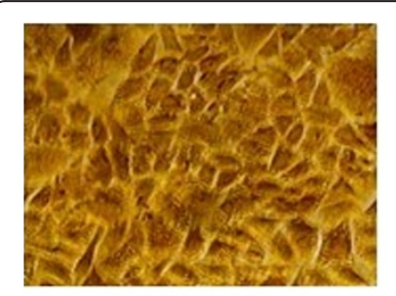

Control

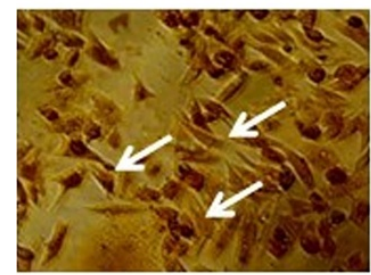

$\operatorname{Emodin}(40 \mu \mathrm{M})$

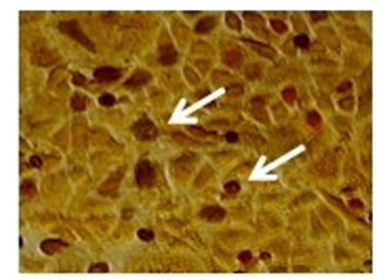

Emodin $(20 \mu \mathrm{M})$

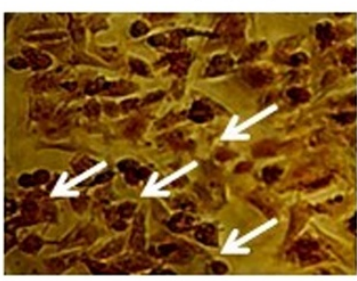

$\operatorname{Emodin}(80 \mu \mathrm{M})$
Figure 2 Cell apoptosis observed using TUNEL staining. HeLa cells were treated with Emodin $(0,20,40$, and $80 \mu \mathrm{M})$ for $48 \mathrm{~h}$. Apoptotic cells exhibited Morphological changes in the nuclei typical of apoptosis. Photographs were taken under an inverted microscope (200x, original magnification). Arrows represent apoptotic cells

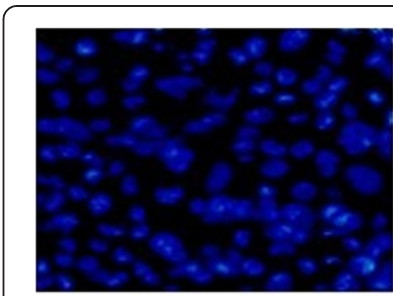

Control

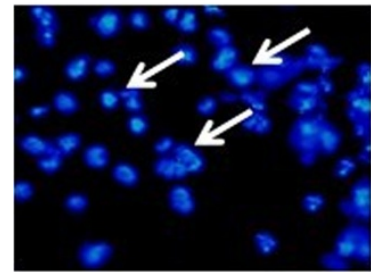

Emodin $(40 \mu \mathrm{M})$

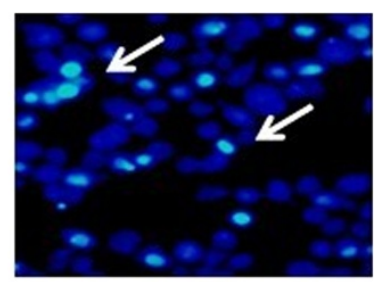

$\operatorname{Emodin}(20 \mu \mathrm{M})$

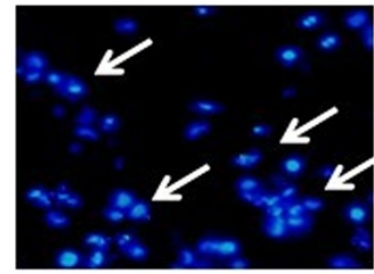

Emodin $(80 \mu \mathrm{M})$
Figure 3 Cell apoptosis observed using Hoechst 33342 staining. HeLa cells were treated with Emodin (0,20,40, and $80 \mu \mathrm{M})$ for $48 \mathrm{~h}$. Apoptotic cells exhibited Morphological changes in the nuclei typical of apoptosis. Photographs were taken under a fluorescence microscope (200x, original magnification). Arrows represent apoptotic cells.

Emodin increased mRNA expression of caspase-8, -9 and 3 Real-time quantitative PCR was used to detect the mRNA expression of Caspase- $9,-8$ and -3 at $48 \mathrm{~h}$ after emodin treatment with emodin $(0,20,40$ and $80 \mu \mathrm{M})$. The change of mRNA expression was normalized by GAPDH expression. The result showed that the mRNA expression of Caspase-9, -8 and -3 increased significantly after treatment with emodin for $48 \mathrm{~h}$ and the upregulation exhibited an emodin dose-dependent pattern (Figure 5).

Emodin increased Cytochome $c$, Apaf-1 but decreased Pro-caspase-9 in intrinsic mitochondrial pathway and increased Fas, FasL, FADD but decreased Pro-caspase- 8 in extrinsic death receptor pathway in HeLa cells.

To further elucidate the molecular mechanism underlying the emodin-induced apoptosis in HeLa cells, we examined the related protein expressions of the intrinsic mitochondrial pathway and the extrinsic death receptor pathway about apoptosis by Western blot.

Western blot analysis was used to further detected protein expressions of Cytochomec, Apaf-1, Caspase-9, Fas, FasL, FADD, Caspase-8, and Caspase-3 in HeLa cells after emodin $(0,20,40$ and $80 \mu \mathrm{M})$ treatment for 48 h. The GAPDH or $\beta$-actin was used as an internal loading control. On one hand, in the present study, emodin treatment increased Cytochromec and Apaf-1 protein expression while it decreased Pro-caspase-9 and Pro-caspase-3 protein expression in treated HeLa cells. The quantitative results showed emodin increased the protein levels of Cytochrome $c$ and Apaf-1 but decreased the protein levels of Pro-caspase- 9 and Pro-caspase- 3 in a dose-dependent manner and the results were 3.23, 


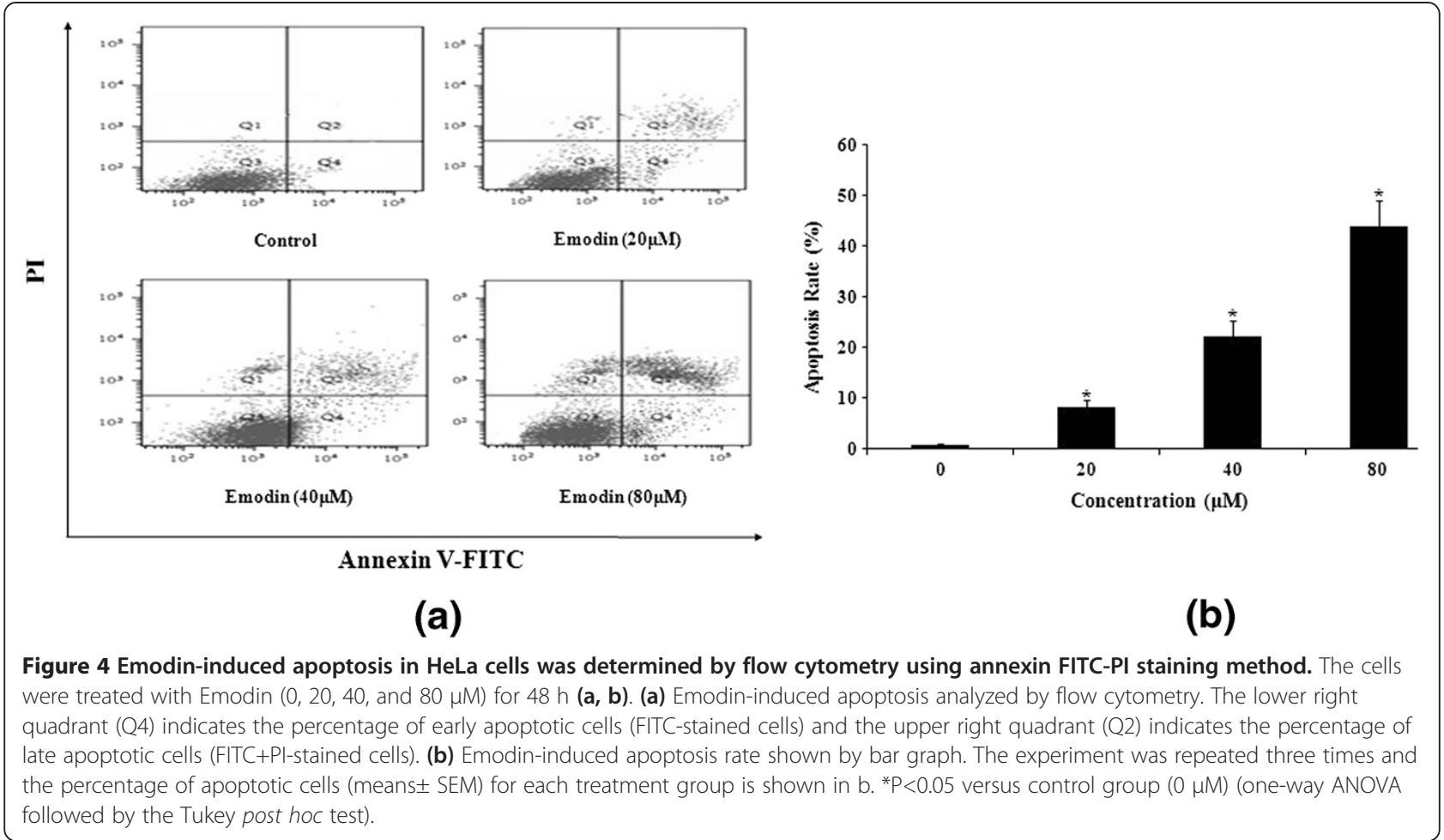

3.42 and $0.36,0.22$ folds of the control level at $80 \mu \mathrm{M}$ (Figure 6a and 6c). On another hand, emodin treatment increased Fas, FasL, FADD protein expression while it decreased Pro-caspase- 8 and Pro-caspase-3 protein expression in treated HeLa cells. The quantitative results showed emodin increased the protein levels of Fas, FasL, FADD but decreased the protein levels of Pro-caspase- 8 and Pro-caspase- 3 in a dose-dependent manner and the

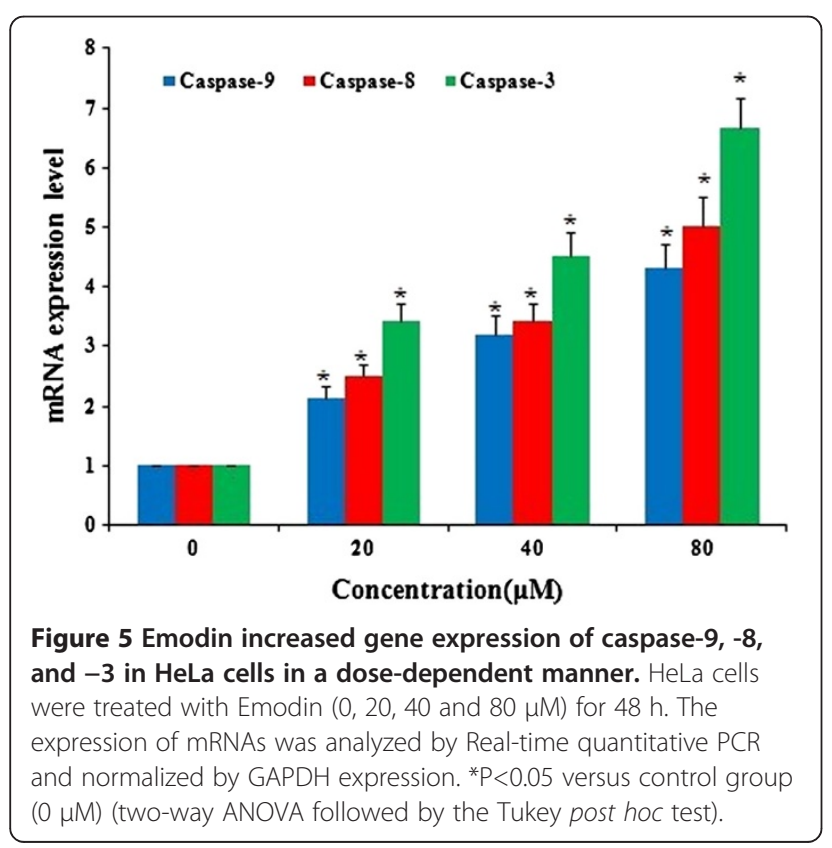

results were $3.76,4.21,4.65$ and $0.31,0.22$ folds of the control level at $80 \mu \mathrm{M}$ (Figure $6 \mathrm{~b}$ and $6 \mathrm{c}$ ). The effect of emodin on regulating the expression of apoptosis-related proteins further supported the observation of emodininduced apoptosis in HeLa cells.

\section{Discussion}

In this study, we have examined the effect of emodin on human cervical cancer cell line HeLa. We observed a dose- and time-dependent anti-proliferation effect of emodin on these cells. The emodin-induced apoptosis might be mediated by the activation of intrinsic mitochondrial pathway and extrinsic death receptor pathway through regulation the expression of related apoptotic factors.

The effect of emodin-induced apoptosis has been previously reported in other cell types [18-27]. It is well known that cell death can be divided into necrosis and apoptosis [28]. Apoptosis is a highly regulated, organized and programmed cell death process controlling the development and homeostasis of multicellular organisms [29], it could kill cancer cells without causing damage to normal cells or surrounding tissues [30]. Thus, induction of apoptosis in cancer cells is a key mechanism by which anticancer therapy works [31]. In this study, we also observed an anti-proliferation effect of emodin on HeLa cells by the induction of apoptosis and this effect exhibited a dose- and time-dependent pattern.

There are two major pathways that could induce apoptosis: the intrinsic mitochondria pathway and extrinsic 


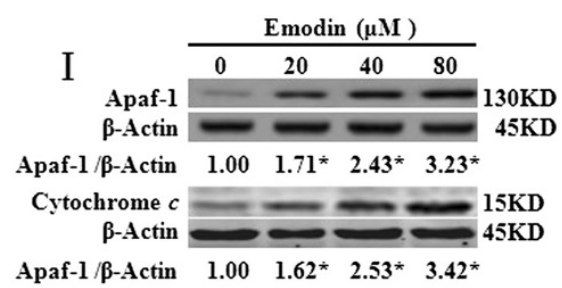

(a)

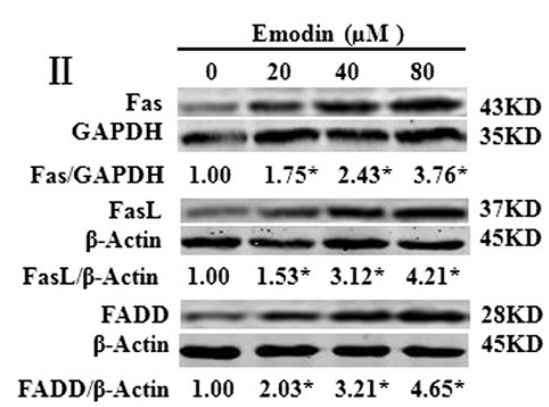

(b)

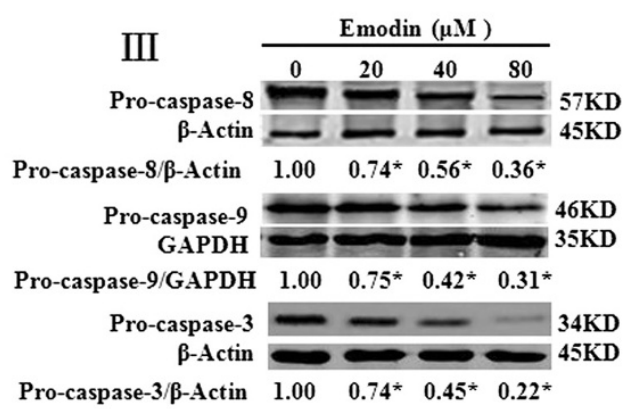

(c)

Figure 6 Emodin increased the expression of Apaf-1, Cytochrome c, Fas, FasL, and FADD but decreased the expression of Pro-caspase-9, Pro-caspase-8, and Pro-caspase-3 in HeLa cells. HeLa cells were treated with Emodin (0, 20, 40 and $80 \mu \mathrm{M})$ for $48 \mathrm{~h}$ and the expression of proteins in treated cells was determined by Western blot analysis. (a), Emodin increased the expression of Apaf-1, Cytochrome c. (b), Emodin increased the expression of Fas, FasL, and FADD. (c), Emodin decreased the expression of Pro-caspase-8, Pro-caspase-9, and Pro-caspase-3. Data are reported as the means \pm SEM of at least three experiments. ${ }^{*}<<0.05$ versus control group $(0 \mu \mathrm{M})$ (two-way ANOVA followed by the Tukey post hoc test).

death receptor pathway $[32,33]$. In the intrinsic pathway, many factors such as environmental changes, stimuli and drugs could induce mitochondria dysfunction. Cytochrome $\mathrm{c}$ is released from dysfunctional mitochondria and accumulated in the cytoplasm where it binds to the protein Apaf-1, meanwhile, binding of Pro-caspase-9 to Apaf-1 oligomers results in the formation of apoptosome, eventually leading to the activation of caspase-3, DNA damage and cell apoptosis [34-39]. Many previous studies have shown that emodin inhibits proliferation and induces apoptosis in many carcinoma cells via intrinsic mitochondria pathway [18-20,22,23,40,41]. Our data also showed that emodin induced up-regulation of Cytochome $c$ and Apaf-1 but down-regulation Pro-caspase-9 and Procaspase-3 in HeLa cells, suggesting the involvement of the intrinsic mitochondria pathway in emodin-induced apoptosis also happened in HeLa cells.

The extrinsic death receptor pathway involves Fas, TNFR1, DR3, DR4 and DR5. In these factors, Fas and FasL have been regarded as very important effectors of apoptosis in various biological conditions and its disregulated expression in a variety of carcinomas such as breast [42], hepatocellular [43], colorectal [44], and nasopharyngeal [45] carcinoma. Fas (CD95 or APO-1) [46], is a $36-\mathrm{kDa}$ cell surface protein that belongs to the death receptor (DR) family. Activation of Fas with its natural ligand FasL, induces apoptosis in sensitive cells [46]. The Fas-mediated cell death pathway includes cell death transactivation adaptor molecular (FADD) with a death domain and a FADD-associated Pro-caspase- 8 that forms death inducing signaling complex (DISC) resulting in apoptotic cell death [47]. Meanwhile, Pro-caspase-8 binds to Fas-bound FADD leading to the activation of Caspase-8 [46], and then leads to the activation of Caspase-3 [48]. This caspase cascade leads DNA degradation, and ultimately cell death [49-52]. Our data showed that emodin induced up-regulation of Fas, FasL, FADD but down-regulation Pro-caspase- 8 and Procaspase- 3 in HeLa cells, these results further support the apoptotic effect of emodin on HeLa cells also via extrinsic death receptor pathway.

In this study, we could conclude that intrinsic mitochondrial pathway and extrinsic death receptor pathway were involved in anti-tumor effect of emodin in HeLa cells. Emodin has been long used by Chinese people as an oral medicine and has been proven to be an effective medicine possesses anti-bacterial, anti-inflammatory, immuno-suppressive, and anti-cancer effects. The antitumor effect of emodin on cervical cancer in vivo and the possible underlying molecular mechanism require 
further study, while emodin has the potential to be developed as a chemotherapeutic or adjuvant agent for human cervical cancers.

\section{Conclusion}

In short, we concluded that the emodin inhibited HeLa proliferation by inducing apoptosis through the intrinsic mitochondrial and extrinsic death receptor pathways.

\section{Competing interest}

The authors declare that there are no conflicts of interest.

\section{Authors' contributions}

WY carried out the studies, YH, ZY, LY, GX participated in the studies. WY and $W X$ conceived of the study, and participated in its design and coordination and helped to draft the manuscript. All authors read and approved the final manuscript.

\section{Acknowledgements}

The study was funded by First Affiliated Hospital of Heilongjiang University of Chinese Medicine.

\section{Author details}

'Department of Gynecology, Third Affiliated Hospital of Harbin Medical University, Hapin Road, 150086, Haerbin, Heilongjiang Province, China. ${ }^{2}$ Department of Gynecology, First Affiliated Hospital of Heilongjiang University of Chinese Medcine, Hapin Road, 150040, Haerbin, Heilongjiang Province, China. ${ }^{3}$ Cardiopulmonary Function Room, Third Affiliated Hospital of Harbin Medical University, Hapin Road, 150086, Haerbin, Heilongjiang Province, China. ${ }^{4}$ Department of General Surgery, Heilongjiang Province's Hospital, Hapin Road, 150036, Haerbin, Heilongjiang Province, China.

Received: 7 March 2013 Accepted: 5 July 2013

Published: 16 July 2013

\section{References}

1. Parkin DM: Global cancer statistics in the year 2000. Lancet Oncol 2001, 2:533-543.

2. World Health Organization.: Comprehensive cervical cancer control: A guide to essential practice. Geneva: WHO; 2006.

3. Fujimoto J: Novel strategy of anti-angiogenic therapy for uterine cervical carcinomas. Anticancer Res 2009, 29:2665-2669.

4. Ma YS, Weng SW, Lin MW, et al: Antitumor effects of emodin on LS1034 human colon cancer cells in vitro and in vivo: Roles of apoptotic cell death and LS1034 tumor xenografts model. Food Chem Toxicol 2012, 50:1271-1278

5. Wang HH, Chung JG: Emodin-induced inhibition of growth and DNA damage in the Helicobacter pylori. Curr Microbiol 1997, 35:262-266.

6. Chang CH, Lin CC, Yang JJ, et al: Anti-inflammatory effects of emodin from ventilago leiocarpa. Am J Chin Med 1996, 24:139-142.

7. Huang HC, Chang JH, Tung SF, et al: Immunosuppressive effect of emodin, a free radical generator. Eur J Pharmacol 1992, 211:359-364.

8. Jing X, Ueki N, Cheng J, et al: Induction of apoptosis in hepatocellular carcinoma cell lines by emodin. Jpn J Cancer Res 2002, 93:874-882.

9. Lai JM, Chang JT, Wen $\mathrm{CL}$, et al: Emodin induces a reactive oxygen species-dependent and ATM-p53-Bax mediated cytotoxicity in lung cancer cells. Eur J Pharmacol 2009, 623:1-9.

10. Chun-Guang W, Jun-Qing Y, Bei-Zhong L, et al: Anti-tumor activity of emodin against human chronic myelocytic leukemia K562 cell lines in vitro and in vivo. Eur J Pharmacol 2010, 627:33-41.

11. Hsu CM, Hsu YA, Tsai Y, et al: Emodin inhibits the growth of hepatoma cells: finding the common anti-cancer pathway using Huh7, Hep3B, and HepG2 cells. Biochem Biophys Res Commun 2010, 392:473-478.

12. Lin SY, Lai WW, Ho CC, et al: Emodin induces apoptosis of human tongue squamous cancer SCC-4 cells through reactive oxygen species and mitochondria-dependent pathways. Anticancer Res 2009, 29:327-336.

13. Cai J, Niu X, Chen YY, et al: Emodin-induced generation of reactive oxygen species inhibits RhoA activation to sensitize gastric carcinoma cells to anoikis. Neoplasia 2008, 10:41-45.
14. Cha $T L$, Qiu $L$, Chen $C T$, et al: Emodin down-regulates androgen receptor and inhibits prostate cancer cell growth. Cancer Res 2005, 65:2287-2295.

15. Wang W, Sun YP, Huang $X Z$, et al: Emodin enhances sensitivity of gallbladder cancer cells to platinum drugs via glutathion depletion and MRP1 downregulation. Biochem Pharmacol 2010, 79:1134-1140.

16. Shi YQ, Fukai T, Sakagami H, et al: Cytotoxic and DNA damage-inducing activities of low molecular weight phenols from rhubarb. Anticancer Res 2001, 21:2847-2853.

17. Chan TC, Chang CJ, Koonchanok NM, et al: Selective inhibition of the growth of ras-transformed human bronchial epithelial cells by emodin, a protein-tyrosine kinase inhibitor. Biochem Biophys Res Commun 1993, 193:1152-1158.

18. Srinivas $G$, Anto $R J$, Srinivas $P$, et al: Emodin induces apoptosis of human cervical cancer cells through poly (ADP-ribose) polymerase cleavage and activation of caspase-9. Eur J Pharmacol 2003, 473:117-125.

19. Wang XD, Gu LQ, Wu JY: Apoptosis-inducing activity of new pyrazole emodin derivatives in human hepatocellular carcinoma HepG2 cells. Biol Pharm Bull 2007, 30:1113-1116

20. Lee HZ, Hsu SL, Liu MC, et al: Effects and mechanisms of aloe-emodin on cell death in human lung squamous cell carcinoma. Eur J Pharmaco 2001, 431:287-295.

21. Shieh DE, Chen $Y Y$, Yen MH, et al: Emodin-induced apoptosis through p53-dependent pathway in human hepatoma cells. Life Sci 2004. 74:2279-2290

22. Qu K, Shen NY, Xu XS, et al: Emodin induces human T cell apoptosis in vitro by ROS-mediated endoplasmic reticulum stress and mitochondrial dysfunction. Acta Pharmacol Sin 2013. Epub ahead of print.

23. Su YT, Chang HL, Shyue SK, et al: Emodin induces apoptosis in human lung adenocarcinoma cells through a reactive oxygen speciesdependent mitochondrial signaling pathway. Biochem Pharmacol 2005, 70:229-241

24. Huang $\mathrm{Q}$, Shen $\mathrm{HM}$, Ong CN: Inhibitory effect of emodin on tumor invasion through suppression of activator protein-1 and nuclear factorkappaB. Biochem Pharmacol 2004, 68:361-371.

25. Yang J, Li H, Chen YY, et al: Anthraquinones sensitize tumor cells to arsenic cytotoxicity in vitro and in vivo via reactive oxygen speciesmediated dual regulation of apoptosis. Free Radic Biol Med 2004 37:2027-2041

26. Olsen BB, Bjorling-Poulsen M, Guerra B: Emodin negatively affects the phosphoinositide 3-kinase/AKT signaling pathway: a study on its mechanism of action. Int I Biochem Cell Biol 2007, 39:227-237.

27. Lee $\mathrm{HZ}$ : Protein kinase $\mathrm{C}$ involvement in aloe-emodin and emodininduced apoptosis in lung carcinoma cell. Br J Pharmacol 2001, 134:1093-1103.

28. Malhi H, Gores GJ: Cellular and molecular mechanisms of liver injury. Gastroenterology 2008, 134:1641-1654

29. Muppidi J, Porter M, Siegel RM: Measurement of apoptosis and other forms of cell death. Curr Protoc Immunol 2004, 3:3-17.

30. Evan Gl, Vousden KH: Proliferation, cell cycle and apoptosis in cancer. Nature 2001, 411:342-348.

31. Kaulmann SH, Earnshaw WC: Induction of apoptosis by cancer chemotherapy. Exp Cell Res 2000, 256:42-49.

32. MacKenzie SH, Clark AC: Targeting cell death in tumors by activating caspases. Curr Cancer Drug Targets 2008, 8:98-109.

33. Repicky A, Jantova S, Milata V: Signal pathways of cell proliferation and death as targets of potential chemotherapeutics. Ceska Slov Farm 2008, $57: 4-10$.

34. Slee EA, Harte MT, Kluck RM, et al: Ordering the Cytochrome c-initiated Caspase Cascade: Hierarchical Activation of Caspases-2, -3, -6, -7, -8, and -10 in a Caspase-9-dependent Manner. J Cell Biol 1999, 144:281-292

35. Lee HJ, Lee HJ, Lee EO, et al: Mitochondria-cytochrome c-caspase-9 cascade mediates isorhamnetin-induced apoptosis. Cancer Lett 2008 270:342-353.

36. Thornberry NA, Lazebnik Y: Caspases: enemies within. Science 1998 281:1312-1316.

37. Oltvai ZN, Milliman CL, Korsmeyer SJ: BCl-2 heterodimerizes in vivo with conserved homolog, Bax, that accelerates programmed cell death. Cell 1993, 74:609-619.

38. Sedlak TW, Oltvai ZN, Yang E, et al: Multiple Bcl-2 family members demonstrate selective dimerizations with Bax. Proc Natl Acad Sci USA 1995, 92:7834-7838. 
39. Mantena SK, Baliga MS, Katiyar SK: Grape seed proanthocyanidins induce apoptosis and inhibit metastasis of highly metastatic breast carcinoma cells. Carcinogenesis 2006, 27:1682-1691.

40. Heo SK, Yun HJ, Park WH, et al: Emodin inhibits TNF-alpha-induced human aortic smooth-muscle cell proliferation via caspase- and mitochondrial-dependent apoptosis. J Cell Biochem 2008, 105:70-80.

41. Chen H, Wei W, Guo Y, et al: Enhanced effect of gemcitabine by emodin against pancreatic cancer in vivo via cytochrome Cregulated apoptosis. Oncol Rep 2011, 25:1253-1261.

42. Mullauer L, Mosberger I, Grusch M, et al: Fas ligand is expressed in normal breast epithelial cells and is frequently up regulated in breast cancer. J Pathol 2000, 190:20-30.

43. Fukuzawa K, Takahashi K, Furuta K, et al: Expression of Fas/Fas Ligand and its involvement in infiltrating lymphocytes in hepatocellular carcinoma (HCC). J Gastroenterol 2001, 36:681-688.

44. Shimoyama M, Kanda T, Liu L, et al: Expression of Fas ligand is an early event in colorectal carcinogenesis. J Surg Oncol 2001, 76:63-68.

45. Abdulkarim B, Sabri S, Deutsh E, et al: Radiation-induced expression of functional Fas ligand in EBV-positive human nasopharyngeal carcinoma cells. Int J Cancer 2000, 86:229-237.

46. Krammer PH, Arnold R, Lavrik IN: Life and death in peripheral T cells. Nat Rev Immunol 2007, 7:532-542.

47. Kischkel FC, Hellbardt S, Behrmann I, et al: Cytotoxicity-dependent APO-1 (Fas/CD95)-associated proteins form a death-inducing signaling complex (DISC) with the receptor. EMBO J 1995, 14:5579-5588.

48. Ashkenazi A: Targeting the extrinsic apoptosis pathway in cancer. Cytokine Growth Factor Rev 2008, 19:325-331.

49. Golks A, Brenner D, Fritsch C, et al: c-FLIPR, a new regulator of death receptor-induced apoptosis. J Biol Chem 2005, 280:14507-14513.

50. Sprick MR, Rieser E, Stahl $H$, et al: Caspase-10 is recruited to and activated at the native TRAIL and CD95 death-inducing signalling complexes in a FADD-dependent manner but cannot functionally substitute caspase-8. EMBO J 2002, 21:4520-4530.

51. Muzio M, Chinnaiyan AM, et al: FLICE, a novel FADD-homologous ICE/ CED-3-like protease, is recruited to the CD95 (Fas/APO-1) death-inducing signaling complex. Cell 1996, 85:817-827.

52. Chang DW, Xing Z, Capacio VL, et al: Interdimer processing mechanism of procaspase-8 activation. EMBO J 2003, 22:4132-4142.

doi:10.1186/1475-2867-13-71

Cite this article as: Yaoxian et al:: Emodin induces apoptosis of human cervical cancer hela cells via intrinsic mitochondrial and extrinsic death receptor pathway. Cancer Cell International 2013 13:71.

\section{Submit your next manuscript to BioMed Central and take full advantage of:}

- Convenient online submission

- Thorough peer review

- No space constraints or color figure charges

- Immediate publication on acceptance

- Inclusion in PubMed, CAS, Scopus and Google Scholar

- Research which is freely available for redistribution 